\title{
Histologische Veränderungen im Gehirn von Meerschweinchen und Kaninchen bei primärer Antiserum-Giftigkeit und bei Einspritzung giftiger Normalsera (carotal-zentraler Ein- spritzung des Serums).
}

\author{
Von \\ E. Friedberger und P. Schröder ${ }^{1}$ ). \\ (Aus dem Hygieneinstitut und der Psychiatrischen und Nervenklinik der Univer- \\ sität Greifswald.) \\ (Eingegangen am 3. Dezember 1921.)
}

Daß antikörperhaltige Sera bei intravenöser Einspritzung für Mecrschweinchen hoch toxisch sein können und den Tod unter dem Symptomenbild akuter Anaphylaxie hervorzurufen imstande sind, wurde bereits vor etwa 11 Jahren von Friedberger ${ }^{2}$ ) beschrieben und in eingehenden Experimenten von Friedberger und Castelli ${ }^{3}$ ) weiter untersucht. Über die Ursache dieser Giftigkeit besteht bei den Autoren noch keine Einigkeit. Die eben erwähnten führen sie, ausgehend von der Tatsache, daß sie nicht dem Antikörpergehalt proportional geht und nach den Untersuchungen von Friedberger und Goretti ${ }^{4}$ ) im Gegensatz zu der Mehrheit der Antikörper an die Albuminfraktion gebunden ist, auf den gleichzeitigen Gehalt solcher Sera an Antikörpern und Antigenresten zurück. Forss ma n n ${ }^{5}$ ), Sachs und Nathan ${ }^{6}$ ), Doerr und Pick 7 ), Orudschiew ${ }^{8}$ ) u.a. erklären speziell die Toxicität der besonders eingehend untersuchten isogenetischen und heterogenetischen Antihammelblutkaninchensera für das Meerschweinchen durch die besonderen Affinitäten, die der

1) Teilwaise vorgatr. Sitzung d. Berl. Mikrobiol. Ges. 11. IV. 21. (B. K.W. 192 I. Nr. 48, S. 1418.)

$\left.{ }^{2}\right)$ Friedberger, Zeitschr. f. Immunitätsforsch, u. exp. Therap., Orig. B, Heft 7, S. 692. 1909.

3) Friedberger und Castelli, Ebenda 6, Heft 1, S. 179.1910.

4) Friedberger und Goretti, Ebenda, Orig. 21, Heft 1-5. 1913.

5) Forssmann, Biochem. Zeitschr. 37, 112. 1911.

$\left.{ }^{6}\right)$ Sachs und Nathan, Zeitschr. f. Immunitätsforsch. u. exp. Therap., Orig. 19, 235. 1913.

`) Doerr und Pick, Ebenda 19, 251. 1913.

8) Orudschiew, Ebenda, Orig. 16, 268. 1913.

Z. f. d. g. exp. Med. XxvI. 
heterogenetische Antihammelamboceptor zu den Organen von Tieren des ,Meerschweinchentypus" (Bail) hat. Auf diese Verhältnisse im einzelnen kann hier nicht eingegangen werden. Es sei auf die einschlägige Literatur und auf deren jüngste kritische Darstellung bei Friedberger und Oshikawa ${ }^{1}$ ) verwiesen.

Jedenfalls besteht aber einwandfrei die Tatsache, daß das intravenös eingespritzte Antihammelblutkaninchenserum Meerschweinchen akut unter dem Symptomenbild der Anaphylaxie tötet.

Nun hat uns Forssma $n^{2}$ ) neuerdings mit einer weiteren höchst interessanten Wirkung derartiger Antihammelblutsera bekanntgemacht.

Werden sie nicht wie gewöhnlich intravenös, sondern in die Carotis nach dem Herzen zu, was wir kurz als , carotal-zentral" bezeichnen wollen, eingespritzt, so entsteht nicht das gewöhnliche Bild der anaphylaktischen Vergiftung, wie sie Friedberger und Castelli als ,primäre Antiserumgiftigkeit" und Forssman als ,umgekehrte Anaphylaxie" deswegen bezeichnet hatte, weil umgekehrt wie beim gewöhnlichen anaphylaktischen Versuch nach seiner Vorstellung dem Tier nicht das Antigen, sondern der Antikörper zugeführt wird und das Antigen im Sinne von Forssman in seinem eigenen Körpergewebe enthalten ist.

Diese Deutung der Serumwirkung im allgemeinen als ,umgekehrte Anaphylaxie" ist auf Grund der von Friedberger und Oshikawa gefundenen Tatsache, daß diese Wirkung nicht nur beim Meerschweinchen, sondern nach carotal-zentraler Applikation auch beim Kaninchen auftritt, wohl nicht mehr aufrecht zu erhalten. Daß es sich aber bei der carotal-zentralen Einspritzung solcher Sera nach Forssman um eine cerebrale Wirkung handeln dürfte, ist nach dem ganzen Symptomenbild sicher. Das eingespritzte Antigen soll bei dieser Applikationsweise, wie Forssman meint, durch die A. vertebralis in das Kleinhirn gelangen und hier toxisch wirken.

Die Symptome, wie sie nun nach carotal-zentraler Einspritzung solcher Sera auftreten, bestehen in Gleichgewichtsstörungen (Manegeund Rollbewegungen, auch Drehungen um die Längsachse) und Störungen der Augenbewegungen, Symptome, die eben von Forssmann auf eine Affektion des Kleinhirns zurückgeführt werden. Häufig, namentlich bei größeren Dosen, tritt auch an Stelle der Zwangsbewegungen eine vollkommene Parese ein.

Die Tiere sterben in der Regel nicht so akut wie bei der Anaphylaxie, sondern häufig erst innerhalb einiger Stunden, selbst erst in $1-2$ Tagen, wobei sie schon in dieser kurzen Zeit die schwerste Abmagerung zeigen.

1) Friedberger und Oshikawa, Zeitschr. f. Immunitätsforsch. u, exp. Therap., Orig. 33, Heft 1, S. 48. 1921.

2) Forssmann, Biochem. Zeitschr. 110, 164. 1920. 
Meerschweinchen und Kaninchen bei primärer Antiserum-Giftigkeit usw. 289

Diese von der seither bekannten Wirkung der primär-giftigen Antisera, d. h. vom anaphylaktischen Symptomenkomplex, so absolut abweichenden Erscheinungen sind nach Forssman bei der zentralcarotalen Einspritzung, wie bereits erwähnt, durch die besonderen Gefäßverhältnisse des Meerschweinchens bedingt. Das toxische Serum soll ,,in einer Konzentration wie sonst nie dem Kleinhirn und den dort befindlichen Zellgruppen zugeführt werden, durch deren Reaktion mit dem Serum der Symptomenkomplex dann ausgelöst wird: . Vielleicht handelte es sich dabei nach ihm auch um eine Aktivierung durch das Blut. Als Ursache nimmt er eine für die betr. hammelhämolytischen Sera spezifische Substanz an, die nach seiner Meinung als ,,verschieden von der intravenös tödlichen Substanz und als eine neue Immunsubstanz aufzufassen ist".

Forssman sowie Friedberger und Oshikawa haben das Symtomenbild im einzelnen eingehend beschrieben. Es sei auf die betr. Veröffentlichungen verwiesen. Hier sei nur noch einmal kurz erwähnt, daß wenigstens in den Versuchen der letztcren Autoren die Gleichgewichtsstörungen eine bemerkenswerte Konstanz zeigten. Manegebewegungen waren fast ausnahmslos gegen den Uhrzeiger gerichtet, Rollbewegungen nach rechts. Auch in der Ruhestellung saB das Tier stets typisch, mit dem Vorderkörper nach links gedreht, so daß eine ausgesprochene Konvexität der rechten Körperseite zustande kam. Ebenso waren die Augenmuskelstörungen typisch. Das linke Auge war fast immer nach dem Schädeldach, das rechte nach der Nasenspitze gerichtet. Der Cornealreflex war stets zuerst rechts erloschen.

Friedberger und Oshikawa haben den Einfluß einer Reihe von Faktoren (Dauer der Injektion, Alter der Tiere, Vagusdurchschneidung, Narkose, Erhitzung, Dialyse, Bindung an Zellen und Organe usw.) auf die Giftigkeit der Antisera bei carotal-zentraler Einspritzung, sowie die Beziehungen zur Anaphylaxie untersucht. Sie haben weiter festgestellt, daß nicht nur die Antihammelblutkaninchensera, sondern auch Normalsera und gewisse tierische Gifte, nicht aber die von ihnen untersuchten chemischen Gifte bei carotalzentraler Einspritzung ähnliche Symptome hervorrufen.

Ausgehend von der Tatsache, daß es sich nach dem ganzen Symptomenkomplex offenbar um eine cerebrale Wirkung mit ganz bestimmter Lokalisation handeln muß, wurden die Gehirne der von Friedberger und Oshikawa benutzten und bei carotal-zentraler Einspritzung eingegangenen Versuchstiere für histologische Untersuchungen herausgenommen, über die im nachstehenden berichtet werden soll.

Die Gehirne wurden sofort nach dem Tod in toto in (mehrmals gewechselten) $96 \%$ Alkohol gebracht, dann im Laboratorium der 
Nervenklinik in Frontalblöcke zerlegt und in Celloidin eingebettet. Von jedem Block wurden kleine Serien geschnitten und nach Nissl, vereinzelt auch mit Hämatoxylin + van Gieson gefärbt.

Von den zur Verfügung stehenden Tieren sind zunächst für die histologische Bearbeitung diejenigen herangezogen worden, bei welchen der Tod nicht sofort oder nach sehr kurzer Zeit eingetreten war, weil bei ihnen mit größerer Wahrscheinlichkeit als bei den unmittelbar gestorbenen auf die Nachweisbarkeit organischer Gewebsveränderungen gerechnet werden konnte. Es sind das acht Meerschweinchen mit einer Lebensdauer von 5 Stunden bis 2 Tagen nach der Injektion, darunter eines (II), das (bei intravenöser Injection) die gewöhnlichen Folgeerscheinungen nicht dargeboten hatte, dazu ein Kaninchen mit 2 tägiger Lebensdauer.

Wir lassen im Nachstehenden zunächst kurz die Protokolle der Injektionen und den histologischen Befund folgen.

\section{A. Meerschweinchenversuche.}

Versuch 1. Meerschweinchen Nr.4, $275 \mathrm{~g}$, erhält 0,1 Antihammelblutserum von Kaninehen $59^{1}$ ) (hämolytischer Titer für Hammelblut 0,0004, Giftigkeit für Meerschweinchen carctal $0,1-0,3 \mathrm{ccm}, \mathrm{i} . \mathrm{v} .=>0,7$ ) in $0,5 \mathrm{Vol}$. carotal-zentral in 5 Sekunden ${ }^{2}$. Sofort typischer Strabismus. Tier legt sich auf linke Seite, rechtes Vorderbein vor linkem, linkes Hinterbein vor rechtem. Tier richtet sich bald wieder auf und sitzt dann in vollkommenem Bogen nach links (Konvexität nach rechts). Gerade gesetzt klappt es sofort wieder wie ein Taschenmesser nach links um. Immer erneute Manegebewegungen, Cornealreflex erhalten. Nach 3 Minuten erneute Manegebewegungen. Tier dreht sich mit der Vorderhand um die Hinterhand als Fixpunkt. Auf die rechte Seite gelegt, fällt es wieder zurück, auf die linke Seite gelegt, bleibt es liegen. Auf Rücken gelegt, zeigt es genau die gleiche Konvexität wie auf dem Bauch. Nach $6^{1 / 2}$ Minuten Cornealreflexe im Erlöschen, Sensibilität erhalten (Kneifen am Ohr). Hält man den Kopf nach links, bleibt der Körper ruhig, dreht man dagegen den Kopf nach rechts, wird das Tier sofort unruhig, dabei starker Widerstand des Kopfes. Nach links Halsmuskulatur vollkommen weich, nach rechts starker Tonus. Schiebt man den Kopf eine Zeitlang nach rechts, so läßt der Tonus nach. Nach 1/2 Minute losgelassen, fliegt aber der Kopf sofort wieder nach links. Unter wiederholten Manegebewegungen erfolgt nach 7 Stunden der Tod.

Sektionsbef und: Bauchorgane intakt, Lunge hyperämisch, leicht gebläht. Gehirn ohne makroskopischen Befund.

Histologischer Befund: Die Durchmusterung der Schnitte von einigen Blöcken aus Großhirn, Kleinhirn und Medulla oblongata. ergibt nirgends das Vorhandensein von herdförmigen Veränderungen. In der Medulla oblongata finden sich überall verstreut einige Ganglienzellen mit gröberen Veränderungen ihres Strukturbildes: Abblassung der färbbaren Substanz bei Nisslfärbung, Anlagerung von feinen und gröberen tiefdunklen Körnchen, Fäden und Brocken an die Oberfläche der Zellen und ihrer Dendriten (sog. Inkrustationen der Golginetze).

1) Vorbehandlung s. Friedberger, Oshikawa a. a. O. S. 54.

$\left.{ }^{2}\right)$ 5-7 Sekunden ist, sofern nicht ausdrücklich anders vermerkt, die Injektionszeit bei allen unsern Versuchen mit carotal-zentraler Einspritzung. 
Meerschweinchen und Kaninchen hei prinärer Antiserum-Giftigkeit usw. 291

Versuch 2. 2. XII. 1920. Meerschweinchen Nr. 5, 330 g, 0,7 Serum vom Kaninchen 59 in die rechte Jugularis. Etwas beschleunigte Atmung und Kaubewegungen. Tier bleibt sonst völlig normal. 3. XII. 1920. 0,3 desselben Serums intravenös. Keine Symptome. Tier bleibt lebend. 5. XII. 1920. Tier ist über Nacht gestorben. Sektion: Magen. und Darm leer, Lunge hyperämisch und ödematös, keine makroskopischen Veränderungen.

His tologischer Befund: Keine als pathologisch verwertbarenVeränderungen in den untersuchten Schnitten.

Versuch 3. 5. XII. 1920. Meerschweinchen Nr. 7, $215 \mathrm{~g}$, erhält 0,5 Normalkaninchenserum in die rechte Jugularis. Keine Symptome.

6. XII. Das Tier erhält 0,1 des gleichen Antiserums wie voriges (Nr. 59) in 0,5 Volum in die rechte Carotis central). Sofort Rollbewegungen, nach 6 Minuten Manegebewegung gegen den Uhrzeiger, Strabismus typisch. Cornealreflex rechts verlangsamt, später ganz erloschen. Immer erneute $\mathrm{Z}_{\text {wangsbewegungen, da- }}$ zwischen typische Zwangsstellung nach links, tot nach 6 St unden, vorher war der Strabismus zurückgegangen.

Sektionsbef und: Keine Besonderheiten, Lunge leicht injiziert, Darm und Nebennieren blaß, Gehirn zeigt makroskopisch keine Veränderungen.

Histologischer Befund: In der Medulla oblongata finden sich in verschiedenen Höhen über sehr weite Strecken des Querschnitts zerstreut, der Schwere nach wechselnd, Gewebsveränderungen auf der ei ne $n$ Seite, scharf abschneidend mit der Mittellinie, sich stark abhebend von den normalen Verhältnissen der andern Seite. Es sind das auf Nisslpräparaten: 1. An den Ganglienzellen: Dunkle klumpigo Massen statt der normalen Zeichnung des Zelläquivalentbildes, weiterhin ,Inkrustationen" (s. Tier I) über Zelleib und Dendriten. Die Kerne dunkel, opak, entrundet. Besonders grob sind diese Veränderungen im Abducenskern und in den großen motorischen Zellen der Substantia reticularis unweit der Raphe, aber auch sonst. Im Gegensatz dazu hat die andere Hälfte der Medulla sehr gut erhaltene Ganglienzellen. 2. An der Glia: Streckenweis die Kerne auffallend klein, tiefdunkel, pyknotisch. 3. Am Grundgewebe: Stellenweis matte Mitfärbung des Grundes auf Nisspräparaten mit körnelig-krümeligem Aussehen.

Versuch 4. Meerschweinchen Nr. 123, $340 \mathrm{~g}$, erhält rechts carotal-zentral 0,05 Serum eines mit Meerschweinchenniere vorbehandelten Kaninchens K. (Titer für Hammelblut $0,0008^{1}$ ), Giftigkeit carotal-zentral $0,02-0,05$, intravenös 0,3 bis 0,5). Sofort typische starke Rollbewegung und typischer Strabismus, Erlöschen des Corneal- und Lidreflexes rechts, nach 3 Minuten sitzt das Tier wieder aufrecht, der Kopf ist um die Längsachse so stark nach rechts gedreht, dal das linke Auge fast nach der Decke gerichtet ist, im iibrigen ist der Körper typisch nach links zusammengeklappt; nach 7 Minuten Erholung bis auf typische Linksstellung, rechts ist der Lidreflex wieder vorhanden, noch nicht aber der Cornealreflex, nach $1 \frac{1}{2}$ Stunden ist auch dieser wieder da. Auch der Strabismus ist zurückgegangen. Das Tier scheint wieder völlig erholt, nur zeigt es sofort wieder die typische Zusammenklappung nach links, sobald man es von der Tischplatte aufhebt und wieder niedersetzt.

29. T. früh: Das Tier liegt auf der rechten Seite, sobald man es auf die linke legt, fällt es sofort zuriick. Durch Heben des Kopfes oder eines Beines werden sofort wieder Rollbewegungen ausgelöst. Temperatur: $31,5^{\circ}$. Cornealreflex rechts erloschen, Lidreflex erhalten, am linken Auge alle Reflexe normal. Das Tier stirbt etwa innerhalb von $24 \mathrm{Stunden}$ nach der Injektion.

Scktions bef und: Lunge etwas gebläht, bla $ß$, Nebenniere etwas hyperämisch sonst ohne Besonderes.

1) Vorbehandlung und Giftigkeit s, a. a. 0. S. 58/59. 
Histologischer Befund: Im oberen Abschnitt der Medulla oblongata ein kleines Herdchen auf der einen Seite, dicht neben der Mittellinie, auf dem Nisslpräparat ganz hell; es enthält nur wenige kleine runde pyknotische Gliakerne, keine Ganglienzellen. Die Ganglienzellen der nächsten Umgebung teils ganz bla $B$, teils mit schwer veränderten Kernen und mit einzelnen dicken Inkrustationen um den Zelleib. Auf derselben Seite, in der das Herdchen liegt, sind die vom Rande der Medulla eintretenden Gefäße dickwandig, mit vermehrten und geschwollenen Endothelien. Nirgends Leukocyten.

Versuch 5. 7. I. 1921. Meerschweinchen Nr. 56, $380 \mathrm{~g}$, erhält 0,1 Antiziegenblutserum Nr. 201) (hämolytischer Titer für Hammelblut 0,0004, Giftigkeit carotal-zentral $0,05-0,1$, intravenös $0,1-0,3)$ in die rechte Carotis in etwa 5 Sekunden. Sofort Manegebewegung gegen den Uhrzeiger, wobei der Kopf völlig atonisch auf dem Tisch ruht; nach I Minute ist das Tier gewissermaßen um seine Längsachse gedreht, indem der Kopf und die Vorderbeine fast nach der Decke gerichtet sind, nach 2 Minuten typische Rollbewegungen, nach 6 Minuten leidlich erholt, nach 1 Stunde erneute Manegebewegungen, typische Stellung nach links, nach 3 Stunden leichte krampfartige Zuckungen, nach 5 Stunden liegt das Tier auf der Seite nach links zusammengeklappt, am rechten Auge deutlicher Strabismus. Unter fortwährend wiederholten leichten Zuckungen und anfallweisem krampfartigen Zittern der Vorder- und der Hinterbeine erfolgt der Tod nach 36 stunden.

Sektionsbefund: Lunge stark hyperämisch, leicht gebläht, sonst keine Besonderheiten.

Histologischer Befund: An mehreren Stellen des verlängerten Markes einige kleine Herdchen von Ölimmersions-Gesichtsfeldgröße und weniger, bestehend aus dicht gedrängten, gelapptkernigen Leukocyten von frischem Aussehen ohne Zerfallserscheinungen wie bei Abscessen; zwischen ihnen liegen verhältnismäßig gut erhaltene Ganglien- und Gliazellen. In der Nachbarschaft mit Leukocyten vollgestopfte Gefäße. Die gefundenen Herdchen liegen auf den untersuchten Schnitten sämtlich auf der gleichen Seite der Oblongata.

Versuch 6. 6. XII. Meerschweinchen Nr. 11, 225 g, erhält wie Nr. 7 zunächst $0, \tilde{5}$ Normalkaninchenserum rechts in die Vena jugularis. Keinerlei Symptome.

7. XII. 1920. Das Tier erhält 0,2 Antihammelblutserum Nr. 59 rechts carotalzentral. Sofort typische Rollbewegungen und Strabismus, nach 5 Minuten richtet sich das Tier etwas auf, Kopf und Vorderbeine jedoch vollkommen ohne Tonus, nach 10 Minuten etwas erholt, typische Stellung, nach $3 / 4$ Stunden ist das Tier noch sehr schlapp und zittert fortwährend, nach $11 / 4$ Stunden typische Manegebewegungen, Tier fällt auf die rechte Seite, doch bleibt der Kopf nach links gerichtet, Körper völlig schlapp, Ptosis der Lider, Temperatur nach 2 Stunden $29,5^{\circ}$, tot nach 48 Stunden.

Sektionsbefund: Nebenniere leicht injiziert, Lunge blaß, etwas gebläht, Gehirn leicht injiziert, im Herzen kein Gerinnsel.

Histologischer Befund: Auf Schnitten aus verschiedenen Höhen der Oblongata fallen vereinzelte capillare GefäBe durch ihren Zellreichtum auf. Bei Immersionsbetrachtung ergibt sich: es sind zum größten Teil Lenkocyten im GefäBlumen (sowohl großkernige mononucleäre wie gelapptkernige), aber auch in der Gefäßw and und der Gefäßscheide (fast ausschließlich gelappte, jedoch auch Elemente, die nach Plasmazellen aussehen), schließlich hie und da vereinzelt oder in Häufchen Leukocyten frei im Gewebe um die Gefäße. Die weißen Blut.

1) Vorbehandlung s. a. a. O. S. 57. Bestimmung der Giftigkeit S. 58. 
körperchen in den Gefäßen liøgen zum Teil verstreut, zum Teil dicht gedrängt, an letzteren Stellen keine Hinweise auf thrombotische Verstopfung im Gewebe, etwa Blutungen oder Erweich ungen.

Im motoriscben V.-Kern der einen Seite in verschiedenen Schnitthöhen dieselben Ganglienzellveränderun sen wie bei Tier 4, nur weniger grob, jedoch gegenüber der anderen Seite mit it ren als normal zu bezeichnenden Zellen sehr stark in die Augen fallend. Die Zel eiber sind zum Teil nur blaß, nicht dunkelklumpig wie bei Tier 4, nur mit zarteı Inkrustationen besetzt, aber die Zellkerne schwe: verändert: mattopak, geschrumpft. Dieselben Zellveränderungen auch an anderen Nervenkernen und Zellgruppen der Oblongata.

Versuch 7. 17. I. 1921. Meerschweinchen Nr. 72, $230 \mathrm{~g}$, erhält rechts carotal 0,02 Antiziegenblutserum Nr. 20 (Sexum s. Versuch 5) in 0,5 Volum, in 9 Sekunden injiziert.

Nach 1 Minute typische :Bollbewegungen, Manegebewegung gegen Uhrzeiger; typischer Strabismus, Reflex links erhalten, rechts erloschen, nach 15 Minuten scheinbar erholt, nach 30 Minuten wieder deutlich typische Rollbewegungen, dann etwas erholt.

19. I. Tier ist stark abgemagert und kalt, moribund, stirbt. Gewicht $150 \mathrm{~g}$.

Sektionsbef und: Dar n und Peritoneum nicht injiziert; Nebenniere leicht injiziert, Herz kein Gerinnsel. Lunge hier nicht gebläht, stark injiziert, keine hämorrhagischen Flecken.

Dieser Versuch gibt uns ain Bild von der kolossalen Giftig keit des Serums, das in dieser kleiren. Menge innerhalb von 2 Tagen einen Gewichtsverlust von $80 \mathrm{~g}$ zur Folge hat.

Histologischer Bef und: Keine gelichteten Bezirke, keine gut abgegrenzten Herde in den untersuchten Schnitten. Aber weit zerstreut, fleckförmig, zum Teil konfluierend, lediglich in des grauen Substanz, einen großen Teil derselben einnehmend, auf der einen Seite (links) erheblich gröber und verbreiteter, leicht erkennbare Gewebsveränder mgen: Die färbbare Substanz der Ganglienzellen ist zerfallen, teils abgeblaßt, teils grob krümelig-bröckelig; Inkrustationen sind nur vereinzelt, aber dann sehr grob, an großen Dendriten von motorischen Nervenzellen zu sehen; die Zellkerre sind dunkel-opak. Zwischen den Zellen im Grau viele kleine Krümel und Körner, das gesamte Gran bei Nisslfärbung matt mitgefärbt. Dazu, stellenweis eichlich, stellenweis spärlich, locker verstreut oder auch gedrängter, zwischen døn Ganglienzellen Leukocyten ohne erkennbare örtliche Bezichungen zu kapillaren oder gröberen Gefäßen.

Friedberger und Oshikawa haben bereits gezeigt, daß den Normalseris in größeren Mengen bei carotal-zentraler Einspritzung die gleiche Giftwirkung wie den Immunseris, so dem normalen Kaninchenserum und dem für Meerschweinchen besonders giftigen normalen Rinderserum, zukommt. Auch in dieser Beziehung ergab sich also, daB die Immunsera die gleichen Qualitäten nur in gesteigertem Maße besitzen, wie sic auch den Normalseris eigen sein können. Auch in einem solchen l'all wurde das Gehirn auf sejne Veränderungen untersucht.

Versuch 8. Meerschweinchen Nr. $19,210 \mathrm{~g}$, erhält rechts carotal-zentral 1,0 normales Rinderserum ( $1 / 2$ Stunde bei $56^{\circ}$ inaktiviert). Nach 7 Minuten tyjische Manegebewegungen, typische Stellung der Beine, Cornealreflex rechts erlosehen, links erhalten. Strabismus typisch. Typische Konkavität nach links. 
Nach 9 Minuten auch der rechte Lidreflex erloschen, links erhalten. Nach 10 Minuten: Tier ist so weit nach links gebeugt, daß die linke Kopfseite auf dem linken Hinterschenkel ruht. Nach 34 Minuten sitzt das Tier wieder gerade, Reflex rechts noch immer erloschen, vereinzelte Krämpfe. Nach 1 Stunde ist das linke Auge in atypischer Weise nach hinten gerichtet, rechts Strabismus wic immer. Das Tier liegt auf der rechten Seite und hat Abneigung gegen die Linkslage. Tot nach 5 Stunden.

Sektion: Lunge blaß, etwas gebläht, sonst ohne Besonderheiten.

Der histologische Befund entspricht dem des Tieres von Versuch 1.

\section{B. Kaninchenversuche.}

Es wurde darauf hingewiesen, daß nach der Vorstellung von Forssman über die giftige Wirkung der Antisera Antihammelblutkaninchensera lediglich für die Tiere des, ,Meerschweinchenty pus" und nicht für solche des ,Kaninchentypus“, also nicht für das Kaninchen selbst giftig sein dürfen.

Doch haben Friedberger und Oshikawa die Giftigkeit derartiger Sera auch für das Kaninchen bei carotal-zentraler Einspritzung gezeigt. Auch hier sind bei den untersuchten Tieren die gleichen Veänderungen im histologischen Bilde vorhanden wie bei den Meerschweinchen. Als Beispiel sei ein derartiger Versuch aufgoführt.

Versuch 9. 10. II. 1921. Kaninchen Nr. 36, 1500 g, erhält 0,2 Antimecrschweinchennierenserum , $\mathrm{K}^{\text {c }}$ rechts carotal in 6 Sekunden. (Das Serum war vorher mit ejner Normalkaninchen-Gehirncmulsion in Kontakt gewesen und abzentrifugiert worden. Diese Prozedur hat, wic die Versuche ergeben haben ${ }^{1}$, keinen Einfluß auf die Giftigkeit.)

Typische Manegebewegung, Corneal- und Lidreflex zunächst beiderseits erhalten, Pupillenreflexe beiderseits geschwunden, Vorderbeine schlaff, Kopf nach links gedreht. Nach 24 Stunden Rollbewegung mit intensivem Schreien; Corneal- und Lidreflex jetzt rechts erloschen, links beides erhalten, links Pupillenreaktion erhalten, rechte Pupille starr. Nach mehrstündiger Ruhe tetanische Krämpfe, nach 3 Minuten beginnt der Krampf sich zu lösen; dann wieder Opisthotonus, Schwanz krampfhaft gegen den Rücken gestreckt, tot nach 28 Stunden.

Histologischer Bef und: Auf den Schnitten eines Blockes, die oben durch die vordere Spitze des Kleinbirns, basal durch den vorderen Teil der Brückenformation gehen, also unweit binter den Vierhügeln liegen, findet sich ein Herd, auf einer Seite, bis unmittelbar an die Raphe heran, nach oben nicht ganz bis heran an das Ependym des sich eben offnenden IV. Ventrikels; er nimmt mit seiner gröBeren Achse die halbe Höhe der Medulla oblongata ein ist nicht ganz so breit, läßt lateral den Facialiskern frei, liegt also vorwiegend (wie der Herd von Kan. 9) in der Substantia reticularis; in seiner Mitte findet sich ein Streifen lesser erhaitenen Gewebes.

Schon makroskopisch ist cr als ein etwa $1^{1 / 2}-2 \mathrm{~mm}$ messender heller Fleck erkennbar. Bei Immersionsvergrößerung zeigt er sich wenig scharf begrenzt. In seinen ganz hellen Partien fehlen Ganglienzellen ganz oder fast ganz; die vorhandenen sind schwer verändert, klein, gleichmäßig gefärbt, opak, geschrumpft.

1) a. a. 0. S. 105 . 
Auch die Zahl der Gliakerne ist gering, die einzelnen sind ganz klein, tiefdunkel, wesentlich unterschieden von den größeren, blasseren, bläschenförmigen der gesamten näheren und wciteren Umgebung; hie und da ein vereinzelter Leukocyt; die Gefäße nicht stärker harvortretend. In der besser erhaltenen Gewebsinsel, die den Herd zum Tejl durchquert, sind die Ganglienzellen erheblich besser gezeichnet, aber auch grob verändert, die Gliakerne dunkel und über das Ganze Leukocyten locker verstreut, i. Endothelkerne der Capillaren schwer verändert, schrumpelig, blaß, im Lumen vielfach Leukocyten, ebenso in der unmittelbaren Umgebung der Gefäße. In den Randpartien der Herde nach der gesunden Ungebung zu fallen an verschiedenen Ganglienzellen ,Inkrustationen " auf, und auch hier sind, stellenwrise recht gedrängt, Leukocyten über das Gewebe zerstreut.

Sonst lassen die Schnitte licser Serie nirgends gröbere Gewebsveränderungen rekennen, ebensowenig die aus zwei weiteren Blöcken der Medulla oblongata und des Kleinhirns.

Auf einen Block weiter olen, dessen gefärbte und aufgclegte Schnitte dorsal durch die hinteren Vierhügel : sehen, basal unmittelbar vor die Brücke fallen, ist die hier an der Basis in der Mittellinie gelegene große Vene prall gefüllt, ihr zur Seite liegen links und rechts die lecren Arterienquerschnitte. An einer umsehriebenen Stelle, nur auf wenigen Schnitten der Serie, liegt der Vene unmittelbar an, innerhalb der Pia, ein Haufe von dichtgudrängten frischen Leukocyten, der etwa die halbe Größe des Venenquerschnittes laat. Wo er der Vene anliegt, ist ihre Wand gleichfalls von Leukocyten durchsetzt un $l$ das Lumen ist prall gefüllt mit frischen roten und sehr vielen, den roten an Zahl fast glcichkommenden weißen Blutkörperchen. Unterhalb des Blockes (in Höle der erstbeschriebenen Schnittserie mit dem Lichtungsherd) ist die Vene leer, waiter oben enthält sie frisches Blut ohne viel Leukocyten.

Das Ergebnis der histologischen Untersuchung ist, daß bei allen 'Tieren, Meerschweinchen wie Kaninchen, bei welchen die klinischen Folgeerscheinungen der curotal-zentralen Einspritzung vorhanden gewesen waren (d.h. lediglish nicht bei II), auch anatomische Veränderungen nachzuweisen waren. Der Sitz dieser Veränderungen ist ausnahmslos die Medulla oblongata, nicht das Kleinhirn, wo Forssman den Sitz der toxischen Wirkung vermutet hatte, und a ch nicht das Großhirn. Klinisch erklärt dieser Sitz der Veränder ungen bei den engen und zahlreichen Verbindungen der Medulla oilongata mit dem Kleinhirn die Symptome während des Lebens austeichend.

Diese histologischen I'eststellungen sind nur Stichproben; es sind keine lückenlosen Serien yreschnitten worden; die Befunde stellen deshalb nur das Minimum ler tatsächlich vorhandenen Veränderungen dar, was ihre quantitative Seite betrifft; ebenso sind sie qualitativ einseitig wegen der einseitigen Untersuchungstechnik (Alkoholfixierung, Nissls Färbung). Sie erliuben infolge davon auch keine lückenlosen Parallelen zwischen klinischen Symptomen und Lokalisation der Veränderungen. Jedoch, das war es auch nicht, woran uns in erster Linie lag; es interessierte uns vielmehr zunächst die Frage des Nachweises 
grober anatomischer Läsionen bei der carotal-zentralen Einspritzung von Antiseris und Normalseris überhaupt. Diesen Nachweis bringen die Befunde lückenlos, und zwar in solchem Maße, daß sie uns ermutigt haben, auch bei der gewöhnlichen anaphylaktischen Vergiftung von neuem nach ähnlichen Veränderungen in den Organen der Tiere zu suchen.

In 3 Fällen (Me. IV, V, Kan. IX) war der Hauptbefund der Nachweis eines oder mehrerer Herdchen in der Oblongata, davon zweimal (außer bei Me. V) genau an der gleichen Stelle, in der Substantia reticularis einer Seite bis unmittelbar heran an die Raphe und nach oben nicht ganz bis an das Ependym des IV. Ventrikels. Es handelt sich dabei um Tiere mit einer Lebensdauer von 1-2 Tagen nach der Injektion. Die Herdehen sind charakterisiert durch eine deutliche, schon makroskopisch (auf dem Nissl-Präparat) erkennbare Abblassung, mikroskopisch durch weitgehenden Ausfall von Ganglienzellen und schwere Veränderungen immer wieder ganz der gleichen Art in den erhalten gebliebenen, sowie gleichfalls stets wieder dieselben Veränderungen an den Gliaelementen (kleine dunkle pyknotische Kerne), welche sich durch ihr Aussehen scharf abheben von allen Teilen außerhalb der Herde; dazu kommen, bei früherem Tod fehlend oder gering, bei späterem z. T. sehr reichlich, Leukocyten, die teils nur locker, teils dicht gedrängt über das Herdgebiet und auch über seine Nachbarschaft verstreut sind ohne erkennbare örtliche Anlehnung an die Gefäße. Bei Me. VI geben den hier multiplen Herdchen die Leukocytenansammlungen geradezu das charakteristische Gepräge, hinter dem die anderen Gewebsveränderungen im Bilde ganz zurücktreten.

In 2 anderen Fällen (Me. III und VII) mit Lebensdauer von 6 bzw. 48 Stunden nach der Einspritzung fanden sich auf den untersuchten Schnitten derartige Herde nicht, dafür weit verbreitet in der grauen Substanz, bei III streng halbseitig, bei VII beiderseitig mit Bevorzugung der linken Seite, schwere Ganglienzellveränderungen, pyknotische Glia und grobe Veränderungen an dem Grundgewebe, auf dem Nisslbilde erkennbar an der diffusen Mitfärbung und an dem Auftreten allerlei unregelmäBiger dunkler Körner und Krümel. Bei Me. III (6 Stunden) fehlen Leukocyten, bei VII (2 Tage) sind sie in den veränderten Gewebspartien teils spärlich, teils reichlich vorhanden. Me. VI (48 Stunden) läßt die gleichen Veränderungen in dem motorischen Trigeminuskern der einen Seite, geringer auch in anderen Teilen erkennen, dazu vereinzelte freie Leukocyten im Gewebe.

Bei Me. I und VIII schließlich beschränkt sich der pathologisehe Befund auf diffus hie und da nachweisbare Ganglienzellveränderungen, wiederum der gleichen Art, wie bei den Tieren III und VII, sowie inner- 
halb der Herde bzw. ihrer Umgebung bei IV und IX. Für sie charakteristisch ist die Sclırumpfung und eckige Gestaltung des Zellleibes, die dunkel-opake Färbung des Kernes und besonders die Anlagerung von feinen oder ६röberen tief dumklen Körnchen, Fäden oder Brocken auf die Oberflächo des Zelleibes, die von $\mathrm{Nissl}$ so genannten „Inkrustationen des Golgiretzes". Es sind das Veränderungen, welche, in der menschlichen Histcpathologie der Hirnrinde bekannt sind als Ausdruck einer besonderen Form der Zellnekrose ${ }^{1}$ ).

Der Gefäßapparat in cer Medulla oblongata der Tiere zeigt mancherlei Pathologisches. Negativ ist der Befund bei den Tieren I-III, welche nur ă-7 Stunden gelebt haben, abgesehen von leichten Veränderungen auf dem Niss,lbilde an den Endothelien, die nicht ohne weiteres als zum Krankhei1svorgang gehörig zu betrachten sind; Me. IV (24 Stunden) ließ auf der Halbseite mit dem Herdchen die von der Pia am Rande der Oblongata einstrahlenden Gefäße verdickt, ihre Endothelien

1) Histologische Veränderangen im Zentralnervensystem (Rückrnmark) nach Serumeinspritzungen sind, soveit wir das aus der Literatur ersehen können, zuerst von Uhle nh uth und M s xter (Fortschr. d. Med. 16, 361; 1898) beschrieben. Doch handelt es sich hier, v'orauf schon Friedberger in seinem SchluBwort (Sitzung der Berliner Mikrobirlogischen Gesellschaft vom 11. IV. 1921, Berl. klin. Wochenschr. 1921, Nr. 48, א. 1418) hingewiesen hat, um vollkommen andere Versuchsbedingungen. Die Tiere wurden mit Normalrinder- und Menschenserum in größeren Dosen mehr nals an aufeinanderfolgenden Tagen bis zu 10 Tagen oder auch in größeren Interval len in die $\mathrm{O} \mathrm{hr}$ ve ne gespritzt. - Was ihre histologischen Untersuchungen anlangt, so stammen sie aus der Zeit, in der man mit NissI noch annahm, in den histologischen Veränderungen des Nervenzell-Äquivalentbildes allein das spezifischs Korrelat für bestimmte Schädigungen des Nervensystems finden zu können. Din Gepflogenheiten der damaligen Zeit entsprechend sind auch nur die großen (motorischen) Ganglienzellen der Hals- und Lendenanschwellung des Rückenmarks untersucht worden. Die beigegebenen guten Abbildungen lassen im wesentlicheu „Chromatolyse mit Schwellung" der Ganglienzellen erkennen, d. h. Veränderungeı, von denen wir wissen, daß sie nach sehr vielen allgemeinen Schädigungen regeln äßig ganz diffus oder weit verbreitet über das Nervensystem auftreten; das schwer 3 Kranksein der Tiere mit grober Abmagerung nach den Einspritzungen würde dafür als Ursache ausreichen, es sei denn, daß der Nachweis der strengen Umschriebe theit auf ganz bestimmte Zellgruppen oder Zellarten erbracht wäre. Dementsprechend betonen bereits die Verff. die Unspezifität der von ihnen beschriebenen Zellveränderungen. In demselben Sinne spricht die Feststellung der Verff., daß die Veränderungen zum Teil am gröbsten waren bei Tieren ohne nervöse Folgeerscheinungen, und ganz gering oder gar nicht vorhanden bei Tod unter sehr schweren Krämpfen. Die von uns beobachteten Nervenzellveränderungen sind dagegen nur Teilerscheinungen von nekrobiotischen Prozessen an allen Gewebselementen mehr oder weniger umschriebener Stellen im zentralen Nervensystem; dazu sind die Gınglienzellveränderungen nicht die von Uhlenhuth und Moxter beschriebenen vieldeutigen, an sich in der Regel reparablen der sog. Chromatolyse, sondern sie entsprechen einer besonderen, sehr schweren, auch sonst bekannten Art, die stets der histologische Ausdruck des unrettbaren Unterganges der Zellen sind. 
geschwollen erkennen; bei Me. V (36 Stunden) mit den multiplen Leukocytenherden waren auch die Gefäße der Nachbarschaft mit Leukocyten vollgestopft; bei Me. VI (48 Stunden) fanden sich verstreut über den Querschnitt stark mit Leukocyten angefüllte und von Leukocyten und Plasmazellen umgebene Capillaren. Von Wichtigkeit, wenn auch schwer deutbar, ist schließlich der Befund bei Kan. IX (28 Stunden), bei welchem lokal, und zwar oberhalb der Stelle des Herdchens, in der Vierhügelgegend, der großen basalen Vene ein in der Pia gelegener und die Venenwand durchsetzender Leukocytenhaufen liegt, während zugleich die Vene stark erweitert und prall mit einem Gemisch von roten und weißen Blutkörperchen gefüllt ist.

Der histologische Befund in allen Fällen läßt eine einheitliche Deutung zu. Es handelt sich um nekrotische Vorgänge. Einfache Gewebsnekrosen sind die mehr diffusen Veränderungen der Fälle III und VII sowie auch VI, im geringeren Grade ebenso die der Fälle I und VIII. Als Gewebsnekrosen, und zwar höchstwahrscheinlich vaskulärer Natur, sind auch die Herdchen der Fälle IV und IX mit ihrer ganz gleichartigen Lagerung dicht neben der Raphe aufzufassen ${ }^{\mathbf{1}}$ ). Sowohl die Ganglienzellveränderungen, wie die der Glia sind beide Male die gleichen, in dem cinen Falle mehr diffus, im anderen herdförmig umschrieben. Kompliziert wird das histologische Bild durch das Auftreten von kleineren oder größeren Mengen Leukocyten, welche diffus über die erkrankten Stellen verstreut sind und keine deutliche Anlagerung an die Gefäße erkennen lassen; sie sind nur vorhanden bei Tieren, die länger gelebt haben, namentlich bei VII und IX, aber auch bei VI (Lebensdauer 28-48 Stunden), nicht bei den früher verendeten (I-IV, VIII). Bei V (36 Stunden) ist das ganze Bild der hier mehrfachen Herdchen beherrscht von Leukocytenansammlungen. Leukocyten im Gewebe gelten vielfach immer noch als sichere Beweise für die entzündliche Natur der in Frage kommenden Vorgänge, vor allem für eine AbsceBbildung. Das ist nicht zutreffend und trifft auch hier nicht zu. Wohl gibt es keine Abscessc ohne massenhafte Leukocyten, aber umgekehrt beweisen Leukocyten nicht die Absceßnatur. Nissl hat schon vor längerem gezeigt, daß der Austritt von Leukocyten eine sehr häufige passagere, wenige Tage dauernde Erscheinung bei allen mög. lichen mit Zerstörung des Gewebes einhergehenden Vorgängen (trau-

1) Ganz das gleiche histologische Verhalten zeigen Hejde, die beim Menschen zusammen mit Arteriosklerose und Lues des Gehirns bekannt und als ,fleckweise Lichtungen" beschrieben worden sind (Schröder, Dtsch. Zeitschr. f. Nervenbeilk. 54, 127; 1915). Die bei unseren Tieren erhobenen Befunde sprechen dafür, daB auch diese fleckweisen Lichtungen beim Menschen keine alten Veränderungen zu sein brauchen, sondern kurze Zeit vor dem Tode entstanden sein können, was bis dahin unentsehieden war. 
Meerschweinchen und Kaninchen bei primärer Antiserum-Giftigkeit usw. 299

matischer, nekrotischer usw., natürlich u. a. auch entzündlicher Art) ist. Bei der zum Absceß führenden Entzündung kommt es immer wieder von neuem zum Austritt weißer Blutkörperchen aus den Capillaren (Dauerwirkung der sich ständig vermehrenden Erreger) und alsdann zur eitrigen Einschmelzung, in den anderen Fällen hört der Austritt rasch auf und die Leukocyten verschwinden ${ }^{1}$ ). Wir haben bei unseren Tieren keine Veranlassung, die Leukocytenansammlungen anders aufzufassen, um so mehr als auch die gesetzte Schädigung an sich schwerlich unter die entzündungs- und speziell die eitererregenden gerechnet werden darf. Darüber endgültig entscheiden könnten nur histologisch untersuchte Fälle, welche länger als die uns zur Verfügung stehenden gelebt haben.

Die Nekrosenbildungen mit thrombotischen oder embolischen Vorgängen in Zusammenhang zu bringen, und überhaupt den GefäBverschluß als die Grundlage der gefundenen Veränderungen anzusprechen, geben die Befunde keinerlei Veranlassung. Bemerkenswert ist das eine, auf eine eigenartige lokale Venenthrombose zum mindesten verdächtige Gehirn des Tieres IX; aber dieser Befund ist vorläufig ganz vereinzelt unter neun geblieben, und auch er erklärt den Lokalbefund keineswegs. Jedenfalls fehlen die bekannten Folgeerscheinungen von arteriellem oder capillarem Gefäßverschluß (Blutungen, Erweichungen) bei allen Tieren völlig.

Die klinischen Symptome bei den Tieren haben ganz überwiegend Halbseitencharakter. Dem entspricht der anatomische Befund insofern, als auch die histologischen Veränderungen teils rein einseitig, teils jedenfalls überwiegend einseitig in der Medulla oblongata sind.

Weshalb die Medulla oblongata, wie es scheint, der ausschließliche Sitz der organischen Veränderungen bei den Tieren ist, d. h. weshalb bei carotal-zentraler Einspritzung von Antihammel-Eiweißseris, also auf dem Wege der Blutbahn, vom Gehirn nur die Medulla oblongata, und obenein fast ausschließlich ihre eine Seite geschädigt wird, ist eine Frage, über die man allerlei Vermutungen äußern kann, über die wir aber gerade so wenig wissen, wie etwa darüber, weshalb der Erreger der Encephalitis lethargica auf seinem Wege die Gefäße zum Linsenkerngebiet bevorzugt, bzw. diese Gebiete vorzugsweise schädigt. Das sind Fragen, die in derselben Richtung liegen, wie die nach der Prädilektion gewisser Teile des Nervensystems überhaupt zu speziellen Erkrankungen, z. B. des Nervus radialis bei Blei-, des Peroneus bei chronischer Alkoholintoxikation. Ob bei alledem die Erörterung rein mechanischer Gesichtspunkte für die Erklärung den Vorzug verdient,

1) Vgl. Schröder, Encephalitis und Myelitis. Monatsschr. f. Psychiatr. u. Neurol. 43, 179.1918. 
300 E. Friedberger und P. Schröder: Histologische Veränderungen usw.

erscheint uns recht fraglich. Jedenfalls aber muß die Giftigkeit des wirksamen Prinzips im Antiserum eine recht beträchtliche sein. $0,2 \mathrm{ccm}$ Antiserum genügten z. B., um ein Kaninchen von $1,5 \mathrm{~kg} \mathrm{zu}$ töten. Rechnet man den Wassergehalt des Kaninchenblutes mit 92,6\%, so bleiben 0,0148 feste Substanz, davon sind 5,4\% Eiweiß $=0,0008$. Erwägt man, daß nach Friedberger und Oshikawa im wesentlichen nur der Albuminanteil wirksam ist, und stellt man diesen mit $2 / 3$ des gesamten Eiweißes in Rechnung, so ergibt sich, daß 0,00053, d. h. $0,53 \mathrm{mg}$ Substanz bereits imstande sind, derartige schwere anatomische Veränderungen hervorzurufen. 